\title{
SUPERLOGO E DESENHOMETRIA: FORMAS DIFERENCIADAS DE APRENDER GEOMETRIA
}

Odair José Pin, Eugenia BrunildaOpazoUribe

Universidade Federal do Mato Grosso do Sul - UFMS, Curso de Licenciatura em Matemática, Três Lagoas, MS. E-mail: odairjosepin@gmail.com

Agência de Fomento: Programa de Educação Tutorial

\section{RESUMO}

O trabalho apresenta resultados de uma atividade de pesquisa desenvolvida na área da educação, com o objetivo de contribuir com o ensino de geometria, através de recursos didáticos manipuláveis e o uso da tecnologia. A proposta é aliar o uso do software SuperLogo, que possui uma interface simples e lúdica, com um jogo inovador baseado na linguagem matriz desse software, buscando com isso atrair o aluno para o ensino de geometria e desenho geométrico. A pesquisa foi desenvolvida através de levantamento bibliográfico, estudo teórico, discussões, apresentação de seminários, preparação de uma oficina com os alunos do curso de Matemática e elaboração do relatório final. O objetivo agora é estudar os impactos diretos que o SuperLogo e o jogo causam nas escolas e no ensino de Matemática em geral.

Palavras-chave: Software, SuperLogo, Jogo, Geometria, Educação

\section{SUPERLOGO AND DESENHOMETRIA: DIFFERENTIATED FORMS OF LEARN GEOMETRY}

\begin{abstract}
The paper presents results of a research activity developed in the field of education, in order to contribute to the teaching of geometry, through learning resources manipulatives and the use of technology. The proposal is to combine the use of SuperLogo software, It has a simple interface and playful, with an innovative game based on this matrix language software, seeking to attract students to the teaching of geometry and geometric design. The research was developed through bibliographical survey, theoretical study, discussions, presentation of seminars, preparation of a workshop with the pupils of the course of Mathematics and preparation of final report. The goal now is to study the direct impacts that SuperLogo and the game cause in schools and in the teaching of Mathematics in General.
\end{abstract}

Keywords: Software, SuperLogo, Game, Geometry, Education 


\section{INTRODUÇÃO}

O ensino de Matemática é um dos grandes desafios que o Brasil enfrenta, desde sempre. Cada vez mais novas tecnologias surgem, novos métodos são implantados, novas informações e novos olhares surgem sobre tudo. Porém, o ensino ficou estagnado no tempo. Diversos fatores implicam para que isso aconteça, desde a falta de interesse diante da inovação, até o desgaste físico de uma sala de aula, onde a matemática, vista de forma tradicional, é desinteressante e perde seu significado. De acordo com os Parâmetros Curriculares Nacionais (PCN):

A constatação da sua importância apóia-se no fato de que a Matemática desempenha papel decisivo, pois permite resolver problemas da vida cotidiana, tem muitas aplicações no mundo do trabalho e funciona como instrumento essencial para a construção de conhecimentos em outras áreas curriculares. Do mesmo modo, interfere fortemente na formação de capacidades intelectuais, na estruturação do pensamento e na agilização do raciocínio dedutivo do aluno. (Brasil, 1997).

Quando se trata de Geometria, esse agravante fica ainda pior. A conexão necessária entre o conteúdo e o cotidiano do aluno não é estabelecida. O conteúdo de Geometria é visto de forma muito rasa, ou não é visto de forma a facilitar uma conexão entre a realidade e o subjetivo, entre o concreto e o abstrato.

Diante de todas essas dificuldades, o objetivo desse trabalho é mostrar um novo olhar para o ensino de Matemática. Um olhar mais dinâmico e humanizado, através de recursos didáticos diferenciados e atuais, que auxiliam na compreensão da geometria plana e desenho geométrico. A proposta é utilizar o software SuperLogo e o jogo "Desenhometria", criado especificamente para este trabalho de pesquisa e que utiliza de ideias semelhantes à linguagem de programação desse software, para proporcionar aos alunos um ensino mais lúdico e significativo, além de divertido. Dentre as diversas capacidades que podem ser trabalhadas com esses recursos, está a capacidade de se orientar no plano, utilizar régua e transferidor, além de conceitos sobre ângulos, plano cartesiano, e classificação de retas.

\section{METODOLOGIA}

O trabalho relata uma atividade de pesquisa realizada no âmbito do Programa de Educação Tutorial que busca estudar os impactos de recursos diferenciados no ensino de um modo geral e como adequar esses recursos para o ensino de Geometria. Para o desenvolvimento do trabalho foram realizadas algumas leituras sobre o uso de recursos lúdicos no ensino básico de Matemática e especificamente para Geometria, foram realizadas discussões, apresentação de seminários e resolução de exercícios sobre os conteúdos, preparação e desenvolvimento de uma oficina que foi aplicada aos alunos do curso de Licenciatura em Matemática, como uma forma de teste, posteriormente foi feita a análise dos resultados da oficina para acrescentar alguma sugestão ou adaptação. A pesquisa ainda está em fase de desenvolvimento, pois como fase final do trabalho será realizada a oficina com alunos deensino básico, avaliação dos resultados, análise da relevância da pesquisa como um todo, e elaboração do relatório final.

\section{RESULTADOS}

Segundo as Orientações Curriculares para o Ensino Médio para Ciências da Natureza, Matemática e suas Tecnologias, o ensino de Geometria não deve ser somente teórico baseado em exercícios abstratos e sem significado, pelo contrário:

o estudo da Geometria deve possibilitar aos alunos o desenvolvimento da capacidade de resolver problemas práticos do quotidiano, como, por exemplo, orientar-se no espaço, ler mapas, estimar e comparar distâncias 
percorridas, reconhecer propriedades de formas geométricas básicas, saber usar diferentes unidades de medida (Brasil, 2006)

Por esse motivo, a nossa pesquisa foi direcionada ao uso de recursos diferenciados em sala de aula, mais especificamente, a utilização de jogos. Nascimento (2016) afirma que "os jogos dentro da sala de aula podem servir como uma forma de introduzir determinado conteúdo ou também para consolidá-lo. Cabe ao professor conhecer aspossibilidades dos jogos, saber utilizá-los e se tornar responsável pelo aceite dos alunos à ludicidade". De acordo com os Parâmetros Curriculares Nacionais (PCN):

Recursos didáticos como jogos, livros, vídeos, calculadoras, computadores e outros materiais têm um papel importante no processo de ensino e aprendizagem. Contudo, eles precisam estar integrados a situações que levem ao exercício da análise e da reflexão, em última instância, a base da atividade matemática. (Brasil, 1997)

Dessa forma, é necessário um recurso que fosse além de uma simples atividade diferenciada, mas que tivesse um contexto significativo para o aluno. Que fosse atrativo, mas não disperso. Assim, é importante aplicar essa atividade deixando claro para o aluno o motivo de estar, por exemplo, utilizando régua e compasso, ou de estar calculando certa medida de ângulo.

Com isso em mente, chegou-se até o software SuperLogo 3.0, que foi criado e disponibilizado pelo Núcleo de Informática Aplicada à Educação da Universidade de Campinas para automatizar unidades robóticas a partir de uma linguagem simples e intuitiva. A base dessa linguagem é o conceito de medidas de ângulos, comprimento e orientação, de forma que o software pode ser um recurso para ensinar e trabalhar com esses conteúdos.

Figura 1. Interface do SuperLogo

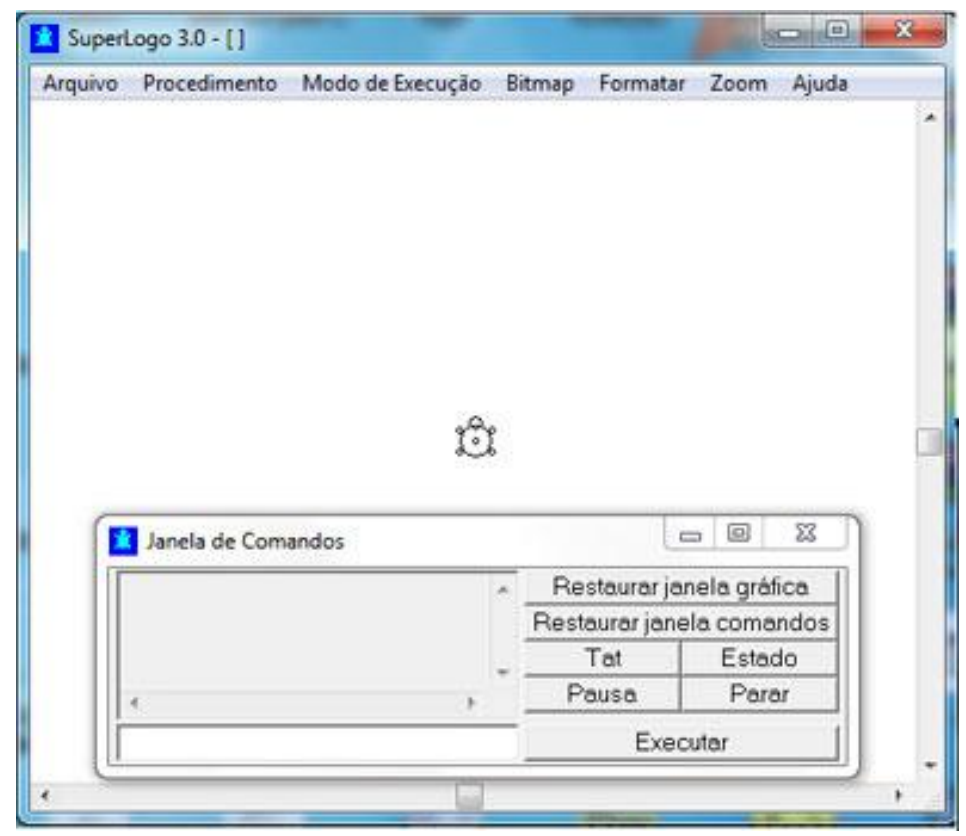

A janela principal do software possui uma imagem semelhante a uma tartaruga, em um ponto central pré-definido, "olhando" para cima. Abaixo dela está uma janela de comandos, onde o usuário determina para onde essa tartaruga irá se movimentar e/ou olhar. Os comandos aqui utilizados são bem simples e intuitivos quanto ao seu resultado: 
- Comando "parafrente"

- Comando "paratrás"

- Comando "paraesquerda"

- Comando "paradireita"

Estes são alguns comandos básicos. "paratrás" e "parafrente" utilizam como medida os "passos". Assim, o número que vier após o comando indica quantos passos a tartaruga vai realizar. "paradireita" e "paraesquerda" são comandos que utilizam como medida o grau. Assim, o número que vier após o comando indica quantos graus a tartaruga vai rotacionar para a esquerda ou para a direita, de acordo com a direção em que ela estiver olhando.

A simplicidade e eficácia do software em trabalhar conteúdos de distância, orientação e angulação possibilitam a exploração de diversas construções, geométricas ou não. Além disso, ele conta com recursos de memorização de procedimentos e escolher qual ferramenta utilizar: utilizar borracha, lápis, ou nenhuma ferramenta se acaso o usuário não quiser que os passos sejam traçados na janela.

Tomando a ideia do software como base, criamos o jogo "Desenhometria". Pensamos em um jogo que fosse acessível e que pudesse ser construído com materiais simples de ser manuseados e encontrados. O jogo foi feito utilizando como base a folha sulfite $A 4$, dividida ao meio verticalmente e horizontalmentepor duas retas que representam os eixos cartesianos. Nessa folha, há quatro quadrados nas pontas, de área $4 \mathrm{~cm}^{2}$ (um para cada ponta da folha), e quatro círculos de diâmetro opcional, um para cada "quadrante" formado (é aconselhável que esses círculos se encontrem perto do centro de cada quadrante, a uma distância considerável dos eixos que dividiram a folha). Um transferidor especial, com marcações angulares de quinze em quinze graus, foi confeccionado a partir de folhas de transparência para retroprojetor. No jogo também há um dado convencional de seis faces e trinta cartas feitas de papel cartão. $\mathrm{O}$ jogo pode ser jogado por até quatro jogadores.

Figura 2 . Desenhometria

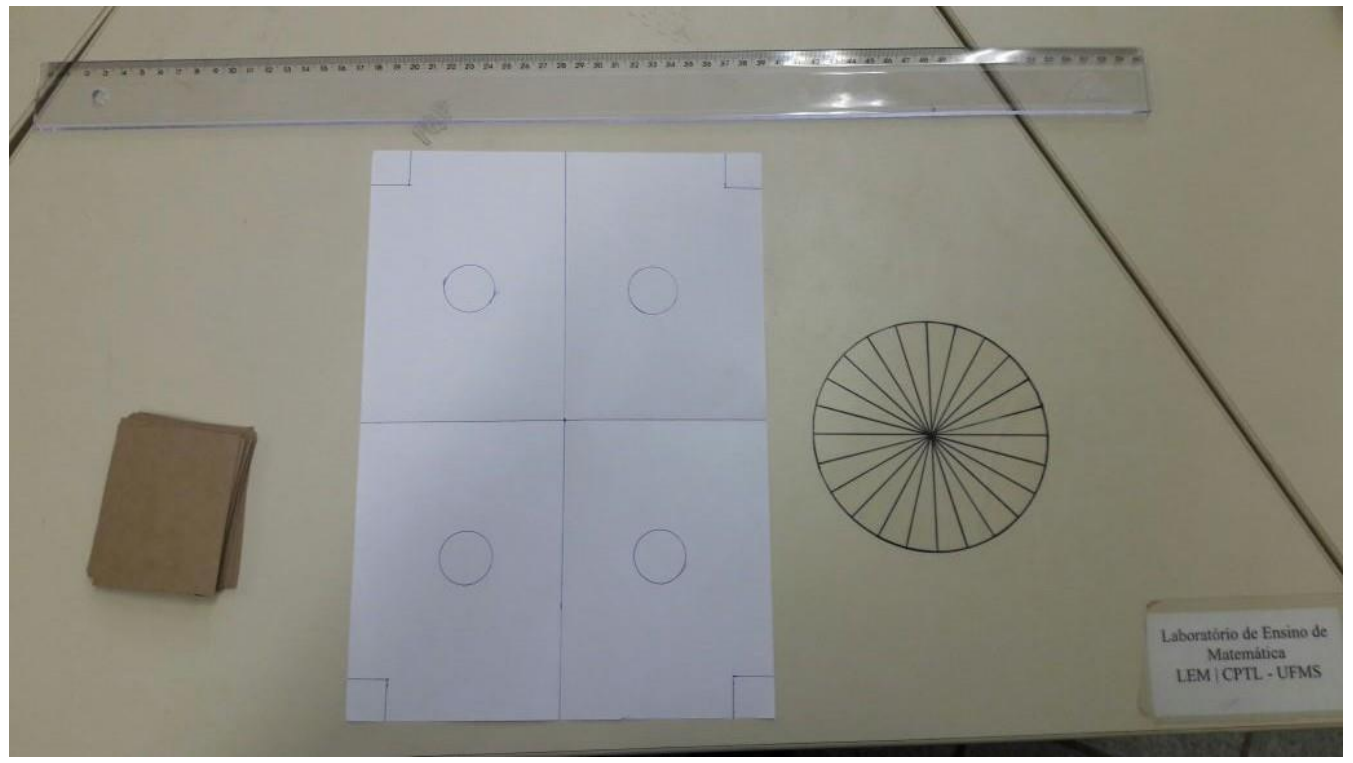

As regras do jogo são bem simples. Todos os jogadores jogam o dado e quem tirar o maior número começa. Caso haja empate, esses jogadores que empataram devem lançar o dado novamente, até que um deles vença. As cartas são embaralhadas e são distribuídas três cartas para cada jogador. O primeiro jogador lança o dado e escolhe uma das três cartas de sua mão para utilizar. O número que ele tirar no dado é a medida em centímetros que ele vai traçar um 
segmento. As cartas dão a informação do ângulo e da orientação que ele deve seguir (direita ou esquerda, ou até mesmo sentido horário e anti-horário do transferidor). Como ponto de partida, a origem do segmento é o ponto de intersecção dos eixos, e o sentido inicial é a semi-reta que representaria o sentido positivo do eixo das abscissas, se relacionarmos as duas retas com os eixos cartesianos. Assim que todos os jogadores traçarem seu primeiro segmento, os próximos segmentos como origem na extremidade do último segmento que o jogador da vez traçou, a direção é sempre dada paralelamente ao seu último segmento, e o sentido é sempre o último que ele realizou.

Há também algumas cartas bônus, que servem para ajudar ou atrapalhar o jogador, com efeitos diferenciados, como avançar $6 \mathrm{~cm}$ ou descartar qualquer carta do jogador adversário, sem ativar o efeito dela. Os círculos no tabuleiro funcionam como armadilhas: caso algum jogador fique parado em cima da área correspondente ao círculo, deve voltar ao início, com origem e sentido padrão. Os jogadores devem pensar com estratégia, já que o objetivo é chegar primeiro até qualquer um dos quadrados das pontas.

Com esse jogo é possível trabalhar também uma noção introdutória de vetores. Porém, o enfoque foi trabalhar na fixação e desenvolvimento da habilidade de desenho geométrico, raciocínio estratégico e noções de ângulos. O jogo não é voltado para uma série específica, podendo ser trabalhado a partir do oitavo ano do Ensino Fundamental. Ele pode ser usado de várias formas diferentes, já que é um material rico de conteúdo.

O próximo passo foi realizar uma oficina, inicialmente com os alunos do curso de Licenciatura em Matemática, para observar os possíveis impactos do jogo em âmbito escolar. Nessa oficina, os próprios alunos confeccionaram o "tabuleiro", utilizaram régua e o transferidor do jogo, que já estava pré-confeccionado. As regras do jogo foram expostas e formaram-se trios para começar a jogar. Logo após a oficina, foi sugerido aos alunos participantes que dessem sugestões de possíveis mudanças e adaptações no jogo.

\section{DISCUSSÃO}

Em geral, a turma foi bem participativa, apesar de não muito numerosa. Durante o jogo, diversas dúvidas surgiram, o que mostra que as regras e a redação das cartas devem ser bem claras e específicas, para que não haja ambiguidade quanto à interpretação. Durante a oficina, foi sugerido que os próprios alunos construíssem o tabuleiro em sala de aula, e alguns alunos perceberam que o modo com as regras e as cartas eram interpretadas interferia diretamente no andamento do jogo, sugerindo algumas alterações. As avaliações do jogo foram bem positivas, e poucas alterações foram feitas para a versão da oficina que será aplicada na escola. A oficina obteve resultados satisfatórios na sua aplicação a alunos de Licenciatura em Matemática, mostrando que pode ser possível aplicar o jogo na escola, desde que o jogo seja aplicado com o propósito apresentado. Como diz Machado (2015):

O jogo como recurso na aprendizagem da matemática no ensino fundamental precisa ser utilizado de maneira criativa, com regras mediadas pelo professor. Essa alternativa inovadora de ensino possibilita uma aprendizagem significativa desde que aplicada de maneira adequada. É preciso desmistificar a visão de que o jogo é apenas uma brincadeira sem objetivos de aprendizagem, que os professores utilizam como dinâmica uma vez ou outra na sala aula.

\section{CONCLUSÃO}

Conclui-se que o jogo, como material didático, além de mais atrativo do que uma aula aplicada de forma tradicional, fornece significado e contexto nos conteúdos trabalhados, possibilitando um entendimento melhor e criando interesse pela matemática, desmistificando-a e 
transformando em algo mais moderno e eficaz. Nosso objetivo maior agora é realizar uma pesquisa de campo, com alunos das redes públicas de ensino, do estado de São Paulo e de Mato Grosso do Sul, a fim de desenvolver um Trabalho de Conclusão de Curso sobre os jogos no âmbito do ensino de Matemática, principalmente na área da Geometria Plana. Além disso, o software SuperLogo e o jogo "Desenhometria" prometem ser recursos didáticos bem ricos e divertidos, por sua simplicidade e atratividade.

\section{REFERÊNCIAS}

1. BRASIL. Parâmetros Curriculares Nacionais: Matemática. Secretaria de Educação FundamentalBrasília: MEC/SEF, 1997. 142p.

2. BRASIL. Ciências da Natureza, Matemática e suas Tecnologias / Secretaria de Educação Básica. Brasília: MEC/SEB, 2006.135p. (Orientações Curriculares Para o Ensino Médio - Volume 2). Disponível em: <http://portal.mec.gov.br/seb/arquivos/pdf/book_volume_02_internet.pdf> Consultado em: 01/04/2017.

3. MACHADO, F.M.; MACHADO, E.J. Os jogos na Aprendizagem Matemática no Ensino Fundamental. Disponível em: <http://educere.bruc.com.br/arquivo/pdf2015/19639_11229.pdf>. Consultado em: 01/04/2017.

4. NASCIMENTO, C. A. F. ; NUNES, F. S. ; MARQUES, J. L. ; HARAB, L. S. R. ; AMADEO, M. S. . O lúdico invade a sala de aula de matemática com os jogos do GEMat / UERJ. In: XII Encontro Nacional de Educação Matemática, 2016, São Paulo. Educação Matemática na Contemporaneidade: desafios e possibilidades, 2016. 